\section{Kompass \\ Onkologie}

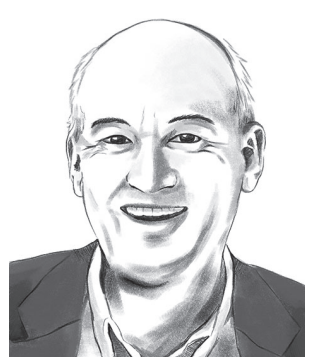

Harald Walach

Poznan/Berlin,

Polen/Deutschland

\title{
Wo gute Ideen herkommen
}

«ldeen», pflegte Einstein zu sagen, «kommen von Gott.» [1] Was er damit wohl meinte? Denn Einstein glaubte ja bekanntlich nicht an Gott im Sinne einer persönlichen, transzendenten Entität, wie das die jüdischchristliche Tradition tut, sondern war Agnostiker. Das heißt: er war sich nicht so sicher, ob es denn eine letzte Realität im Kosmos gibt und wenn ja, wie man sich diese vorstellen muss. Also meinte er mit dieser Aussage wohl etwas anderes: Ideen, so könnte man übersetzen,wirklich gute und neue Ideen, kommen aus einem Bereich «jenseits». Neue Ideen, die wirklich etwas verändern, Lösungen für Probleme bringen oder ganz neue Wege aufzeigen, die müssen ihrer Natur nach völlig neu sein, also nicht aus dem Bestand dessen genommen werden, was wir ohnedies schon haben. Gute wissenschaftliche Theorien, wie etwa Einsteins Relativitätstheorie oder die Quantentheorie, waren solche neuen, guten Ideen. Niemand vorher hatte diese Idee jemals gedacht, und wenn man allen Wissensbestand zusammennimmt, kommt diese Idee nirgends darin vor, selbst wenn man alles verinnerlicht hätte, was es je zu wissen gab. Technisch gesprochen könnte man sagen: Gute, neue Ideen sind nicht algorithmierbar. Sie sind nicht durch das Programmieren irgendeiner Maschine zu gewinnen. Sie kommen von «jenseits», aus einer Einsicht, einer Inspiration. Wie kommt man dazu, solche guten Ideen zu haben?

Mal auf jeden Fall nicht dadurch, dass man sich neue Leitlinien, Qualitätssicherungshandbücher oder Routinen zurechtlegt. Denn all das sind Algorithmen. Sie sind un- serer impliziten Meinung geschuldet, alles, auch im Menschen, sei berechenbar. Diese stammt letztlich daher, dass Descartes den Vorschlag gemacht hat, alle Organismen als Automaten zu betrachten [2]. Ursprünglich eine absolut aberwitzige Konzeption in den Augen und Ohren des zeitgenössischen Publikums, hat sie sich durchgesetzt. Wir betrachten heute den Organismus und den Geist als Automaten oder Computer. Alles muss logisch sein und regelhaften Gesetzen folgen. Dabei entgeht einem: Man kann mit diesem Vorgehen nur das Altbewährte und Altbekannte ordnen, aber nie etwas Neues, Kreatives erfinden.

\section{Ursprünglich eine absolut aberwitzige Konzeption in den Augen und Ohren des zeitgenössischen Publikums, hat sie sich durchgesetzt. Wir betrachten heute den Organismus und den Geist als Automaten oder Computer.}

Das Neue kommt von jenseits. Jenseits der Algorithmen, jenseits der Qualitätssicherung, jenseits der Leitlinien, jenseits der Programme. Und das scheint noch immer, trotz aller Rechenmacht moderner Computer, die Domäne des Menschen zu sein. Kein Computer kann, meines Wissens, bislang etwas wirklich Neues erfinden, nur aus dem Bekannten etwas herausfiltern, das aussieht als wäre es neu, aber eigentlich im Bekannten versteckt ist. Wie reichen wir an dieses Jenseits heran? Einstein, das wissen wir, pflegte seine Arbeit niederzulegen und zwischendurch Geige zu spielen. Er zog sich zurück und ließ seinen Geist frei, legte all die algorithmischen Prozesse zur Ruhe, die stärker mit unserer linken Gehirnhälfte assoziiert sind und erlaubte all den unbewussten Prozessen ihren Raum. Diese sind es, die Sinn, Einsicht, Freude, ja auch Verankerung im Leben und in der Erfahrung vermitteln [3]. Wir müssten also - eigentlich in die tägliche Routine - immer wieder Zeiten und Aktivitäten einstreuen, die uns helfen, an dieses Jenseits heranzukommen. Je mehr wir den Glauben an die Computerisierung der Welt und aller Abläufe bestärken, umso mehr verlieren wir diesen Zugang, scheint mir. Wer also eine wirklich neue Idee haben will, der muss diesem Jenseits Raum geben. Zeit, am besten täglich, in der nichts passiert, keine Analyse, keine Informationsverarbeitung, nichts, Stille, einfache Präsenz. Die alten Mystiker sprachen davon, dass dann Gott zu ihnen spräche. Aus diesem Raum des Jenseits. Mit neuen Ideen. Das ist es, was wir brauchen, kein neues Qualitätssicherungshandbuch.

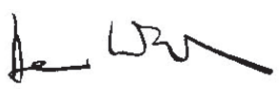

Prof. Dr. Dr. phil. Harald Walach

\section{Literatur}

1 Brian D: Einstein - A Life. New York, Wiley, 1996, p. 61.

2 Descartes R: Treatise of Man (Traité de l'Homme). Transl. and comment. by Thomas S. Hall. Amherst, NY, Prometheus Books, 2003, orig. 1664.

3 McGilchrist I: The Master and His Emissary: TheDivided Brain and the Making of the Western World. New Haven, Yale University Press, 2009. information@karger.com

www.karger.com/kko
(C) 2020 S. Karger GmbH, Freiburg

Karger"
Prof. Dr. Dr. phil. Harald Walach

CHS Institut

Schönwalder Straße 17, 13347 Berlin, Deutschland

hw@ chs-institute.org 